\title{
Study on Interactions between Plasma Proteins and Polymer Surface
}

\author{
Hiroko SATo, Hiroyuki Morimoto,* Akio NAKAJIMA, \\ and Yasuharu NoISHIKI** \\ Research Center for Medical Polymers and Biomaterials, \\ *Department of Polymer Chemistry, Kyoto University, \\ Kyoto 606, Japan \\ **Institute for Thermal Spring Research, Okayama University, \\ Misasa, Tottori 682-02, Japan
}

(Received July 8, 1983)

\begin{abstract}
Plasma proteins at high concentrations were found to be adsorbed on a synthetic material surface as a multimolecular layer. However, at low concentrations, albumin, globulin, and fibrinogen molecules were adsorbed on the material surface as a Langmuir-type monomolecular layer. The adsorption rate constants of plasma proteins were evaluated for segmented polyether urethane nylon, poly(vinyl alcohol), materials containing relatively hydrophobic groups, and glass. The initial stage at which plasma starts to come into contact with these materials was taken into consideration. The good antithrombogenecity of segmented polyether urethane nylon was concluded to be due to its selective adsorption of albumin.

KEY WORDS Antithrombogenecity / Adsorption / Plasma Proteins Segmented Polyether Urethane Nylon / Polypeptide Block Copolymers /
\end{abstract}

The antithrombogenecity of certain materials seems to depend on their surface properties and is determined more or less by complicated blood coagulation and platelet aggregation mechanisms. The major component proteins in blood plasma such as albumin, globulin, and fibrinogen, however, interact first with synthetic materials ${ }^{1}$ because of their higher diffusion coefficients compared with blood cells. Many studies on the adsorption of plasma proteins onto synthetic material surfaces have been carried out in regard to their antithrombogenecity.

We found from in vivo tests that a segmented polyether urethane nylon, PEUN, and an ABA type block copolymer, EBE-20, containing $\operatorname{poly}(\gamma$-ethyl L-glutamate) as the A component and $19.4 \mathrm{~mol}^{\circ} \%$ polybutadiene as the $\mathrm{B}$ component, had good antithrombogenecity. Therefore, attention should be direcred to the interactions of plasma proteins with PEUN and EBE-20, and a comparison made with those of various materials such as poly(vinyl alcohol) (PVA), poly(dimethyl siloxane) (PDMS), poly( $\gamma$-benzyl L-glutamate) (PBLG), certain ABA block copolymers, and glass as a reference. To investigate the adsorption and desorption of proteins on and from various material surfaces, we used polymer-coated glass beads ${ }^{2}$ rather than proteins labeled with radio isotopes.

\section{EXPERIMENTAL}

\section{Samples}

Glass beads of $21.3 \mathrm{~cm}^{2} \mathrm{~g}^{-1}, c a .1 \mathrm{~mm}$ in diameter, were polymer-coated with $0.1 \%$ polymer solutions in the following manner: PEUN (MW, 50,000), obtained from Toyo Cross Co., in dimethylformamide, PVA (MW, 83,000 ), prepared by Kuraray Chemical Co., in $\mathrm{H}_{2} \mathrm{O}$, PDMS of the medical grade, pur- 
chased from Fuji Systems Co., in $\mathrm{H}_{2} \mathrm{O}, \mathrm{PBLG}^{3}$ (MW, $2.81 \times 10^{5}$ ), in a mixture of $\mathrm{CHCl}_{3}$ and trifluoroethanol (TFE), three ABA block copolymers, LBL-12 and LBL-42, ${ }^{3}$ containing PCBL as the A component and 12 and 42, respectively, $\mathrm{mol} \%$ polybutadiene as the $\mathrm{B}$ component, and EBE-20, ${ }^{4}$ in a mixture of $\mathrm{CHCl}_{3}$, TFE, and a minor amount of trifluoroacetic acid. The chemical structure of PEUN is expressed as follows.

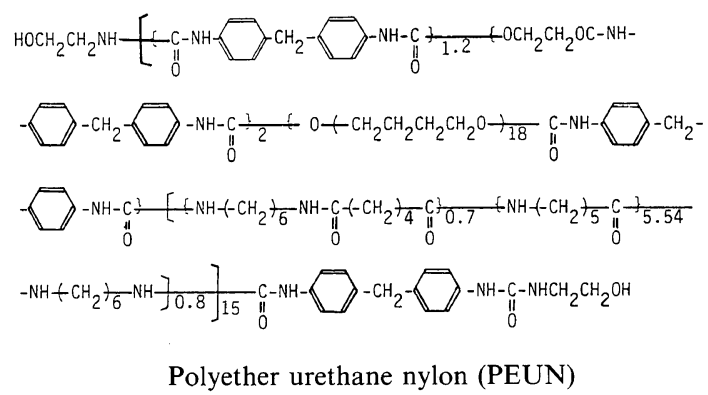

The solution and material properties of PEUN will be published elsewhere.

The polymer-coated glass beads were kept in vacuo for $15 \mathrm{~h}$. Only the PVA-coated glass beads were heated at $120^{\circ} \mathrm{C}$ for $20 \mathrm{~min}$ to bring about an increase in the crystallized phase of PVA. The extent of the polymer-coating on glass beads was $30 \mathrm{mg} \mathrm{m}^{-2}$ for PEUN and $15 \mathrm{mg} \mathrm{m}^{-2}$ for LBL-12, as calculated from the difference in polymer concentrations before and after coating. Hence, the thickness of the polymer-coated layer on the glass beads, assuming the coated surface to be smooth was in the range from 120 to $230 \AA$.

Coated glass beads of $0.1915 \mathrm{~m}^{2}$ in total surface area and $90 \mathrm{~g}$ in weight, were packed into a column $16 \mathrm{~mm}$ in diameter and $260 \mathrm{~mm}$ in length, and rinsed with a $0.05 \mathrm{M}$ phosphate buffer at $\mathrm{pH} 7.4$ before pouring the protein solutions. Plasma proteins used were bovine plasma albumin (Lot. 12F-9365) and bovine plasma $\gamma$-globulin of $99 \%$ electrophoretic purity (Lot. 116c-0147), both obtained from Sigma Chemical Co., and bovine plasma fibrinogen (Lot. 26), 95\% clottable, purchased from Miles Laboratory Inc. The plasma protein solution concentrations were determined from absorbance at $280 \mathrm{~nm}$, using a Hitachi Model EPS-3T spectrophotometer. The specific extinction coefficients of $1 \mathrm{mg} \mathrm{ml} \mathrm{m}^{-1}$ albumin, globulin, and fibrinogen solutions per cm light path were $0.667,1.12$, and 1.506 , respectively.

\section{Methods}

The isotherm and kinetics of protein adsorption on polymer-coated glass beads were investigated, keeping the column at $25^{\circ} \mathrm{C}$ and the relative humidity at $60 \%$, after protein solution had been poured the column with a syringe. The protein solutions were incubated for $2 \mathrm{~h}$ in the column for the adsorption isotherm experiment. The amount of protein was calculated from the concentration difference, caused by adsorption, multiplied by the void volume, obtained experimentally, of the coated glass beads per unit area. The structural change in the albumin desorbed from the surface of the polymer-coated glass beads was measured with a Jasco J-20 CD/ORD spectropolarimeter equipped with a quartz cell having a path length of $1 \mathrm{~mm}$.

The antithrombogenecity of both PEUN and EBE-20 was tested in vivo; for this purpose a surgical silk suture coated with polymer from a $1.5 \%$ polymer solution was placed in a mongrel dog's vein and left for two weeks. The specimens were examined for antithrombogenecity by optical microscopy. In addition, the protein adsorbed on EBE-20 and PEUN was studied in vitro by immuno-electron microscopy ${ }^{5,6}$ by following procedures after immersing the polymer sample in human blood containing sodium citrate for two hours: 1) The specimens after being sufficiently washed in $0.01 \mathrm{M}$ phosphate buffer at $\mathrm{pH} 7.4$ were fixed in $2.5 \%$ glutalaldehyde solution of the buffer. 2) They were then allowed to react with antiserum, i.e., anti-human serum from rabbit, obtained from Behring Institute, West Germany. 3) After being again washed, those 
specimens were allowed to undergo a second antigen-antibody reaction, i.e., a reaction with peroxidase-labeled anti-rabbit IgG from goat, obtained from Fuji Zoki Co., Ltd., Japan. 4) On this occasion, the specimens were oxidized by $0.05 \% 3,3^{\prime}$-diaminobenzidine tetrahydrochloride purchased from Dojindo Laboratory, Japan, and $0.1 \mathrm{ml}$ of $30 \% \mathrm{H}_{2} \mathrm{O}_{2}$ in phosphate buffer. 5) The oxidized specimens after being washed were fixed with a $1 \%$ osmiun tetroxide aqueous solution and after dehydration in ethanol, embedded in epoxy resin and observed with a JEM-100C electron microscope at $80 \mathrm{kV}$.

\section{RESULTS AND DISCUSSION}

Blood plasma is a solution of relatively high protein content from 60 to $80 \mathrm{mg} \mathrm{ml}^{-1}$. Such a high concentration, however, was not suitable for our adsorption experiment, because of the possible experimental error that would be involved. Figure 1 shows adsorption isotherms of albumin, globulin, and fibrinogen solutions onto PDMS-coated glass beads. It is evident that the protein adsorption curve becomes relatively flat in a concentration range around 0.6 to $0.8 \mathrm{mg} \mathrm{ml}^{-1}$. If albumin, globulin, and fibrinogen molecules adsorb separately on the polymer-coated glass beads as a monomolecular layer, the calculated amounts of protein adsorbed should be 2.5-6.0, 2.714.8 , and $2.4-22.4 \mathrm{ml} \mathrm{ml}^{-2}$, respectively, depending on the molecular orientation, i.e., side and end orientation, of the protein molecules on the polymer surface. ${ }^{2,7}$ Hence, plasma proteins can be considered to be adsorbed as a monomolecular layer in the relatively flat region of the isotherm, where the amounts of protein adsorbed are from 5 to $15 \mathrm{mg} \mathrm{m}^{-2}$ near $1 \mathrm{mg} \mathrm{ml}^{-1}$ of protein solution. However, each plasma protein appeared to be adsorbed as a multimolecular layer in a concentration region above $1.5 \mathrm{mg} \mathrm{ml}^{-1}$.

This adsorption isotherm representing a multimolecular layer of plasma proteins has not been reported from observations at low protein concentrations, ${ }^{1,8,9}$ but has been at high protein concentrations for albumin ${ }^{10}$ and globulin ${ }^{11}$ labeled with radio isotopes, and for albumin $^{2}$ and fibrinogen ${ }^{12}$ using polymercoated glass beads. In addition, Matsuda et al. observed under electron microscope that plasma components were adsorbed at a thickness of $c a$. semi-micrometer on the surface of segmented polyurethane material used to assist

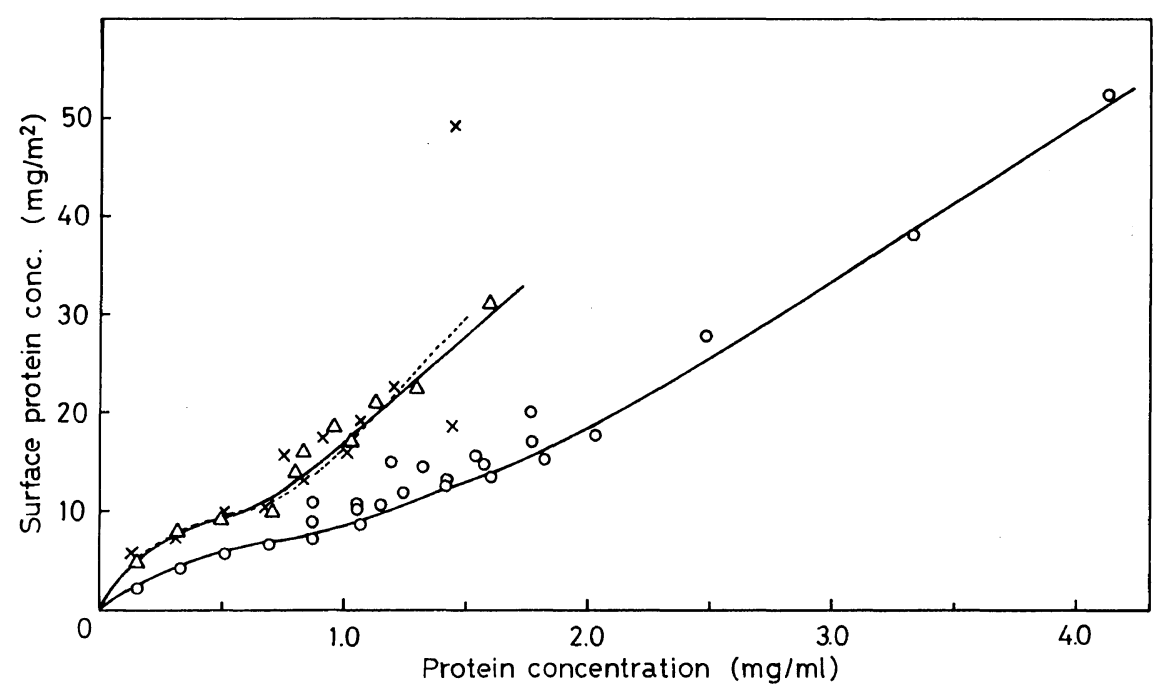

Figure 1. Adsorption isotherms of albumin $(\bigcirc)$, globulin $(\triangle)$, and fibrinogen $(x)$ on PDMS. 
the goat hearts functioning during periods of 42, 52, and 70 days. ${ }^{13,14}$

Although blood which contains various proteins and blood cells, flows at a given velocity, the antithrombogenecity under the condition of static adsorption at low protein concentrations should be considered first. This is because the behavior of plasma proteins is related to at least to the initial stage during which synthetic materials come into contact with the blood and begin interacting with major protein components. This initial stage should lead to the formation of the monomolecular layer and the Langmuir-type adsorption formula expressed below as eq 1 was assumed to apply when estimating the amount of saturated adsorption, $a$, and the proteins were assumed to completely cover the surface of polymercoated glass beads as a monomolecular layer.

$$
1 / x=1 / a+1 /(K a) \cdot 1 / c
$$

$x, c$, and $K$ indicate the amount of protein adsorbed, the equilibrium protein concentration, and a constant, respectively.

The saturated amounts of protein adsorbed on the polymer-coated glass beads are listed in Table I, where albumin and globulin are abbreviated as Alb and Glo, respectively. Among the $a_{\mathrm{Glo}} / a_{\mathrm{Alb}}$ values shown in the last column in Table I, the smallest value corresponds to PEUN; the values for block copolymers con- taining polypeptides are essentially the same as those of the homopolypeptides. It was assumed that the coating solutions of the block copolymers were too dilute to bring about a thick polymer layer on the glass beads and to a microheterophase separation. Therefore, the material surface of PBLG, LBL-12, and EBE20 was each investigated on the basis of protein adsorption kinetics. For example, the time dependence of albumin adsorption on various material surfaces is depicted in Figure 2. Albumin was adsorbed onto the PEUN surface at a much faster rate than onto other material surfaces.

The adsorption rate is expressed by eq 2 ,

Table I. Saturated amounts of plasma proteins adsorbed on material surfaces

\begin{tabular}{lrrrr}
\hline & \multicolumn{3}{c}{$a$} \\
\cline { 2 - 3 } Material & \multicolumn{3}{c}{$\mathrm{mg} \mathrm{m}^{-2}$} & \\
& \multicolumn{3}{c}{$a_{\mathrm{Glo}} / a_{\mathrm{Alb}}$} \\
& Albumin & Globulin & \\
\cline { 2 - 4 } & & & \\
\hline PEUN & 10.3 & 17.9 & 14.3 & 1.74 \\
Glass & 9.5 & 19.2 & 13.7 & 2.02 \\
PVA & 1.9 & 6.6 & 11.6 & 3.47 \\
PDMS & 7.6 & 14.5 & 17.0 & 1.91 \\
PBLG & 4.9 & 13.7 & 11.6 & 2.80 \\
LBL-12 & 6.1 & 16.1 & - & 2.64 \\
LBL-42 & 6.3 & 13.3 & - & 2.11 \\
PCBL & 6.1 & 12.8 & - & 2.10 \\
EBE-20 & 4.6 & 11.2 & - & 2.43 \\
\hline
\end{tabular}

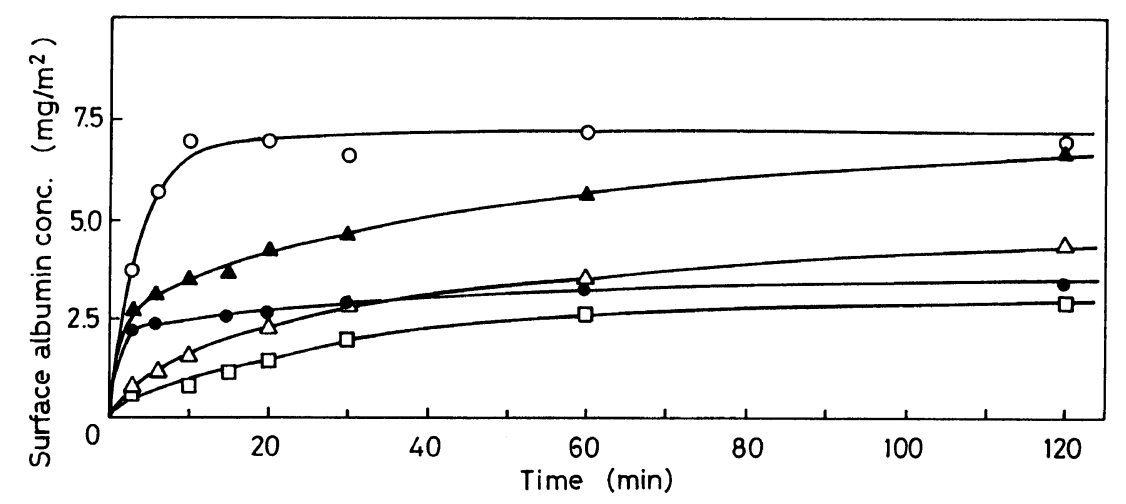

Figure 2. Adsorption kinetics for PEUN (○), glass $(\boldsymbol{\Delta})$, PVA $(\triangle)$, PDMS $(\bullet)$, and PBLG $(\square)$ in $1 \mathrm{mg} \mathrm{ml}^{-1}$ albumin solution. 
assuming the Langmuir-type adsorption of plasma proteins.

$$
\frac{\mathrm{d} x}{\mathrm{~d} t}=k_{\mathrm{L}}(a-x)
$$

On integrating,

$$
\ln \frac{a}{a-x}=k_{\mathrm{L}} t
$$

where $k_{\mathrm{L}}$ is the rate constant of Langmuir-type adsorption. The rate constants of plasma proteins in blood should be related to the proper rate constants of proteins unless special changes in molecular properties occur. If the rate constants determined by the adsorption kinetics expressed in eq 2 increase in proportion to the concentration of the protein solution, the adsorption kinetics of albumin in blood, as plotted in Figure 2, may be assumed to proceed 42 times faster than that in a $1 \mathrm{mg} \mathrm{ml}^{-1}$ solution, at least in the initial adsorption process, since the albumin concen-

Table II. Calculated adsorption rate constants in plasma

\begin{tabular}{lcccc}
\hline \multirow{3}{*}{ Material } & \multicolumn{3}{c}{$k_{\mathrm{L}, \mathrm{pl}}$} & \\
& \multicolumn{3}{c}{$\min ^{-1}$} & $\begin{array}{c}\left(k_{\mathrm{L}, \mathrm{pl}}\right)_{\mathrm{Alb}} / \\
\left(k_{\mathrm{L}, \mathrm{pl}}\right)_{\mathrm{Glo}}\end{array}$ \\
\cline { 2 - 4 } & Albumin & Globulin Fibrinogen \\
\hline PEUN & 7.27 & 0.72 & 0.15 & 10.1 \\
Glass & 4.49 & 1.77 & 0.45 & 2.5 \\
PVA & 2.10 & 1.08 & 0.13 & 1.94 \\
PDMS & 4.91 & 2.20 & 0.10 & 2.2 \\
PBLG & 0.92 & 1.41 & 0.13 & 0.65 \\
LBL-12 & 2.48 & 1.79 & - & 1.39 \\
EBE-20 & 2.35 & 1.68 & - & 1.40 \\
\hline
\end{tabular}

Table III. Protein adsorption in human blood

\begin{tabular}{|c|c|c|c|c|}
\hline \multirow{2}{*}{ Material } & \multicolumn{3}{|c|}{ Protein adsorption (in vitro): } & \multirow{2}{*}{$\begin{array}{l}\text { Antithrom- } \\
\text { - bogenecity } \\
\text { (in vivo) }\end{array}$} \\
\hline & Albumin & Globulin & Fibrinogen & \\
\hline PEUN & ++ & + & + & + \\
\hline EBE-20 & + & - & - & - \\
\hline
\end{tabular}
and antithrombogenecity in canine veins tration in plasma is $42 \mathrm{mg} \mathrm{ml}^{-1}$. Thus, the saturated amounts of protein adsorbed, as listed in Table I, were used as the values of a in eq 2. The kinetic quantities, $\ln \{a /(a-x)\}$, for albumin, globulin, and fibrinogen were replotted against time divided by $42.0,22.4$, and 5.6, respectively. The slopes of these plots provide a basis for calculating the adsorption rate constants, $k_{\mathrm{L} \text {, pl }}$, of proteins in plasma onto synthetic materials. In Table II, these values are summarized for each protein adsorbed onto various materials. Despite the rough assumption for deducing $k_{\mathrm{L}, \mathrm{pl}}$, the index has meaning as relative rate constants for the initial adsorption in plasma. It is clear that the PEUN surface has a large $k_{\mathrm{L}, \mathrm{pl}}$ value for albumin, compared with that of other materials and selectively adsorbs albumin in plasma, as shown in Table II.

Figure 3 shows immuno-electron micrographs of PEUN and EBE-20 adsorbed by three proteins after being immersed in blood. The plasma proteins labeled indirectly with peroxidase were found to contact PEUN and EBE-20 coated on the silk suture. The protein adsorption levels onto PEUN and EBE-20 are listed in Table III. The level of proteins covering the surrounding materials was evaluated as negative, slightly positive, positive, and strongly positve, and represented as,-+ , ++ , and +++ , respectively. The level of antithrombogenecity was evaluated as -, no thrombus adhesion;,$+ c a .25 \%$ thrombus adhesion onto materials;,$++ c a .50 \%$ thrombus adhesion onto materials; +++ , thrombus covering the entire material surface; ++++ , blood vessel blocked. On this basis, the antithrombogenecity of the silk suture as a reference was evaluated as +++ , because the entire surface of the silk suture was covered with thrombus. The antithrombogenecity of PEUN and EBE-20 may be concluded as good on the basis of the in vivo test results. Figure 3 shows a greater amount of albumin was adsorbed on the PEUN surface than globulin or fibrinogen, but a relatively less amount of 


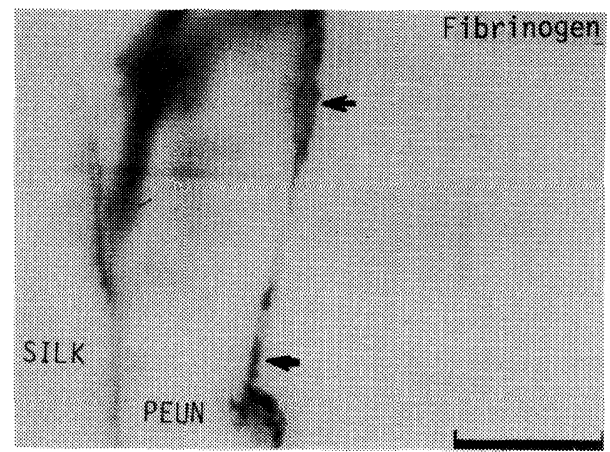

(3)

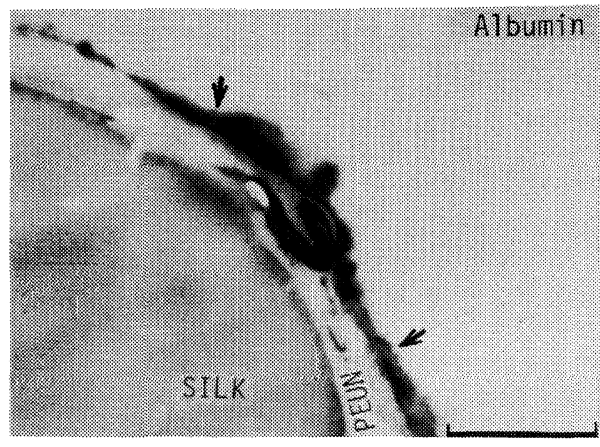

(1)

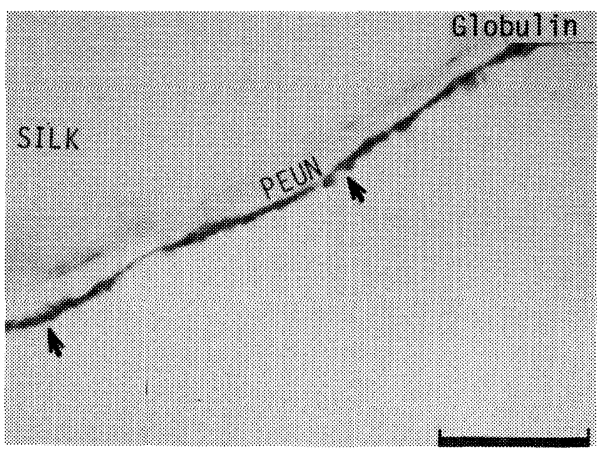

(2)

Figure 3(1)

protein on the EBE-20 surface. These results do not contradict those in Tables I and II, obtained from adsorption experiments with single protein solutions.

A comparison of the constants appearing in the adsorption isotherm and kinetic equation for block copolymers containing polypeptides with those for homopolypeptides shows no remarkable differences as evident from Tables I and II. Under electron microscope, the shadowed surface of PCBL was almost smooth, while that of LBL-15 had round convexities about $500 \AA$ in size on a relatively flat matrix phase. ${ }^{15}$ Although the surface area of LBL-15 is larger than that of PCBL owing to the numerous convexities, the amount of proteins adsorbed on LBL-12 was unexpectedly similar to that on PCBL. That is, it is possible that a microheterophase structure of LBL-12 is not formed on the glass bead surface because of a concentration as low as $1 \mathrm{mg} \mathrm{m}{ }^{-1}$. But the surface of the LBL-12-coated glass beads has better wettability than that of PCBL, ${ }^{15}$ and thus the chain portions including hydrogenbond forming residues situated between the $\mathrm{A}$ and B block chains may exist at the surface of LBL-12-coated glass beads. Taking the existence of similar chain portions in EBE-20 into consideration, it seems reasonable that both block copolymers may have similar adsorption rate constants for albumin despite the differences in hydrophobic side chain groups in polypeptides.

In regard to the plasma proteins desorbed from PEUN, glass, and PVA, irreversible structural changes in desorbed protein were found from CD spectra after one incubation process in a minor amount of buffer solution for $3 \mathrm{~h}$ or $23 \mathrm{~h}$. The structural change in $\gamma$ globulin was evaluated by the ellipticity values 


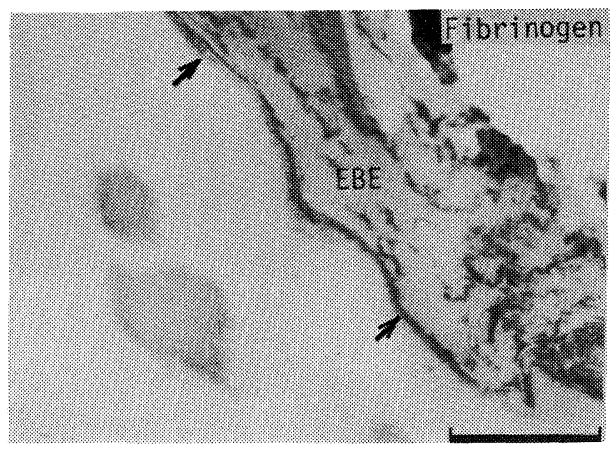

(3)

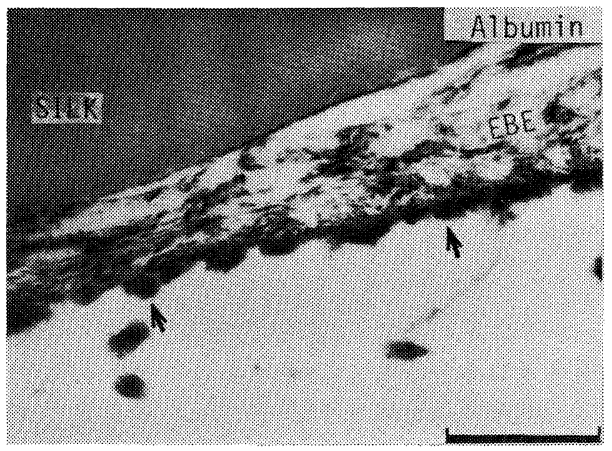

(1)

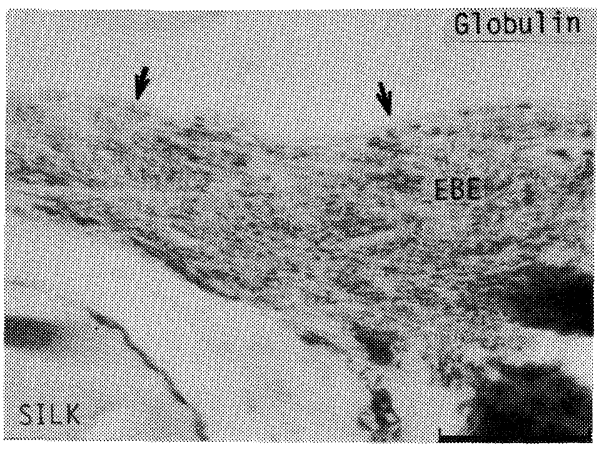

(2)

Figure 3(2)

Figure 3. Immuno-electron micrographs of plasma proteins adsorbed on PEUN and EBE-20 in human blood. Bar indicates $1 \mu \mathrm{m}$.

at $218 \mathrm{~nm}$ because of the predominant content of $\beta$-sheet. ${ }^{2,16}$ The ellipticity change from 80 to $90 \%$ of the native $\gamma$-globulin was observed for each material irrespective of the incubation period. However, such changes may be due to experimental errors arising from the low protein concentrations used in the $\mathrm{CD}$ measurements.

The content of $\alpha$-helix and $\beta$-sheet in albumin and fibrinogen was computed by the procedure of Chen, Yang, and Chau. ${ }^{17} \mathrm{We}$ also used the numeral 10 for our computation as the average number of amino acid residues per helical segment in either albumin or fibrinogen. Table IV shows the results for structural changes in albumin and fibrinogen desorbed from PEUN, glass, and PVA. No noticeable effects brought about by incubation
Table IV. Structural changes in albumin and fibrinogen desorbed from various materials

\begin{tabular}{|c|c|c|c|}
\hline \multirow{2}{*}{ Albumin } & $\alpha$-Helix & $\beta$-Sheet & $\begin{array}{l}\text { Random coil } \\
\text { conformation }\end{array}$ \\
\hline & $\%$ & $\%$ & $\%$ \\
\hline (Native) & $67(100)$ & $16(100)$ & $17(100)$ \\
\hline PEUN & 49 (73) & $9(56)$ & $42(247)$ \\
\hline Glass & $45 \quad(67)$ & $8 \quad(50)$ & $47(276)$ \\
\hline PVA & $57 \quad(85)$ & $10 \quad(63)$ & 33 (194) \\
\hline \multirow{2}{*}{ Fibrinogen } & $\alpha$-Helix & $\beta$-Sheet & $\begin{array}{l}\text { Random coil } \\
\text { conformation }\end{array}$ \\
\hline & $\%$ & $\%$ & $\%$ \\
\hline (Native) & $31(100)$ & $10(100)$ & $59(100)$ \\
\hline PEUN & $29 \quad(94)$ & $12(120)$ & $59(100)$ \\
\hline Glass & $29 \quad(94)$ & $12(120)$ & $59(100)$ \\
\hline PVA & $27 \quad(87)$ & $13(130)$ & $60(102)$ \\
\hline
\end{tabular}


time could be observed for either protein as was the case for globulin. The $\alpha$-helical content of desorbed fibrinogen was estimated to be about $90 \%$ of the native one, as shown in Table IV. Since the $\alpha$-helical structure in fibrinogen has been reported to be less than one half following adsorption on glass, ${ }^{18}$ our desorbed fibrinogen was presumed not to reflect the molecules closely adsorbed on glass; these molecules would not be desorbed from glass simply by incubation treatment in the buffer. However, it is concluded that the structures of $\alpha$-helix and possibly that of the $\beta$-sheet in albumin molecules are disrupted primarily through adsorption onto PEUN and glass, and that a milder disruption of native albumin structure can be expected in the case of desorption from PVA than from PEUN or glass. The percentage of albumin desorptions from PEUN, glass, and PVA following incubation in the buffer were $32,32,58 \%$, respectively. Thus, the good antithrombogenecity of PVA ${ }^{19}$ is considered to arise from the relatively loose interaction between proteins and the hydrogel layer consisting of PVA and water.

PEUN and glass interact more strongly with albumin to cause structural disruption in the albumin molecules. However, the selective adsorption of albumin on PEUN forms the multi-molecular layer, resulting in the good antithrombogenecity of PEUN, as suggested for segmented polyether urethane. ${ }^{1}$ Albumin molecules easily adsorb fatty acids, lipids, e.g., bilirubin, and surfactants, and moreover bring about changes in the ordered structures through adsorption of hydrophobic segments. $^{20-22}$ It appears reasonable that the surface free energy contributed by hydrophobic and hydrophilic microheterophase structures of PEUN are well matched ${ }^{13}$ with those of the inside of albumin molecules easily cleavaged. ${ }^{21}$ A good balance of hydrophobic and hydrophilic segments due to microheterophase separation may bring about the selective adsorption of albumin onto the surface of PEUN.
Acknowledgements. A part of this work was supported by a grant from the Ministry of Education, Science, and Culture of Japan (No. 57550567).

\section{REFERENCES}

1. D. J. Lyman, J. L. Brash, S. W. Chaikin, K. G. Klein, and M. Calini, Trans. Am. Soc. Artif. Intern. Organs, 14, 250 (1968).

2. M. E. Soderquist and A. G. Walton, J. Colloid Interface Sci., 75, 386 (1980).

3. Y. Noishiki, Y. Nakahara, H. Sato, and A. Nakajima, Artif. Organs, 9, 678 (1980).

4. G-W. Chen, H. Sato, T. Hayashi, and A. Nakajima, Bull. Inst. Chem. Res., Kyoto Univ., 59, 267 (1981).

5. Y. Noishiki, J. Biomed. Mater. Res., 16, 359 (1982); Artif. Organs, 11, 794 (1982).

6. P. K. Nakane and G. B. Pierce, Jr., J. Cell. Biol., 33, 307 (1967).

7. E. E. Uzgiris and H. P. M. Fromageot, Biopolymers, 15, 257 (1976).

8. R. G. Lee and S. W. Kim, J. Biomed. Mater. Res., 8, 251 (1974).

9. P. V. Dulm and W. Norde, J. Colloid Interface Sci., 91, 248 (1983).

10. J. L. Brash, S. Uniyal, and Q. Samak, Trans. Am. Soc. Artif. Intern. Organs, 20, 69 (1974).

11. E. Nyilas, T-H. Chiu, and G. A. Hezlinger, Trans. Am. Soc. Artif. Intern. Organs, 20, 480 (1974).

12. T-H. Chiu, E. Nyilas, and D. M. Lederman, Trans. Am. Soc. Artif. Intern. Organs, 22, 498 (1976).

13. T. Matsuda, K. Hayashi, H. Takano, Y. Taenaka, S. Takaichi, M. Umetsu, T. Nakamura, T. Tanaka, T. Nakaya, S. Takaya, and T. Akutsu, Prepr. Jpn. Soc. Biomaterials, 4, 120 (1982).

14. Y. Taenaka, T. Matsuda, H. Takano, M. Umezu, K. Hayashi, T. Nakamura, and T. Akutsu, Artif. Organs, 12, 395 (1983).

15. K. Kugo, Y. Hata, T. Hayashi, and A. Nakajima, Polym. J., 14, 401 (1982).

16. B. Jirgensons, Makromol. Chem., 44/46, 123 (1961).

17. Y-H. Chen, J-T. Yang, and K-H. Chau, Biochemistry, 13, 3350 (1974).

18. M-C. Chau and J-L. Brash, J. Colloid Interface Sci., 82, 263 (1981).

19. Y. Ikada, H. Iwata, F. Horii, T. Matsunaga, N. Taniguchi, M. Suzuki, W. Taki, S. Yamagasa, Y. Yonekawa, and H. Handa, J. Biomed. Mater. Res., 15, 697 (1981).

20. R. G. Reed, R. C. Feldhoff, O. L. Clute, and T. Peters, Jr., Biochemistry, 14, 4578 (1975).

21. R. V. Decker and J. F. Foster, Biochemistry, 5, 1242 (1966).

22. Y. Inoue, S. Sase, R. Chujo, M. Sogami, and S. Nagaoka, Biopolymers, 18, 373 (1979). 